\title{
Forensic body fluid identification: state of the art
}

This article was published in the following Dove Press journal:

Research and Reports in Forensic Medical Science

10 February 2016

Number of times this article has been viewed

\section{SA Harbison \\ RI Fleming}

Forensic Biology, Institute of Environmental Science and Research Ltd, Mt Albert Science Centre, Auckland, New Zealand
Correspondence: SA Harbison

Forensic Biology, Institute of

Environmental Science and Research

Ltd, Mt Albert Science Centre, Private

Bag 92021 , Auckland I 142, New Zealand

Tel +6498153969

Fax +6498486046

Email sallyann.harbison@esr.cri.nz
Abstract: Body fluid identification is a key component in the forensic scientists' tool box and has been carried out both at the crime scene and in the laboratory for many years. Historically, methods relied on (bio) chemical-based tests, many of which lacked specificity. In this review, current technologies for identifying body fluids are described including the use of RNA (mRNA and miRNA), epigenetics, spectroscopic techniques such as Raman spectroscopy and microspectrophotometry, biosensors, and immunochromatographic methods which are outlined alongside their strengths and weaknesses. The potential for new insights into the identification of cells from new technologies such as massively parallel sequencing is explored.

Keywords: forensic science, body fluid identification

\section{Introduction}

Body fluid identification is an important component in forensic science, as the ability to identify body fluids, such as blood and semen, is often the key in a criminal investigation and is subsequently relied upon in court. Many body fluid stains are invisible, present in very small quantities or mixtures, and so identification is not always straightforward. Historically, tests relied on the use of chemical or enzymatic assays that were often presumptive in nature and generally limited in specificity or sensitivity, whereas confirmatory tests relied on microscopic or immunological tests. Many of the early tests were incompatible with DNA profiling and consumed already limited biological material.

Body fluids and tissues of interest in forensic science include blood, menstrual blood, semen, saliva, vaginal material, and skin. Any test for their localization and/or identification should be sensitive, easy to use in the laboratory or at the crime scene, specific both to the body fluid and preferably to the species (human), and nondestructive, allowing subsequent analysis by DNA profiling. As body fluids can be deposited on a variety of surfaces, tests also need to be able to work successfully on different substrates. DNA profiling has become increasingly sensitive with the development of new multiplexes and there is a need for complementary body fluid identification tools. ${ }^{1}$

Recent advances in the area of body fluid identification have resulted in a number of new approaches and methodologies enabling 1) the definitive identification of some body fluids for the first time, 2) new tests facilitating nondestructive testing at the crime scene for further analysis with fast and effective DNA profiling, and 3) laboratory-based RNA and protein techniques enabling the specific identification of single cells. 
This review describes the current status of body fluid identification, including the evaluation of newly available tools demonstrating their potential applications to forensic casework. Earlier reviews cover some of these aspects. As it is not possible to include all relevant references in any one review, we have included key references to illustrate specific points where appropriate. ${ }^{2-5}$

\section{Chemical and immunologically based tests}

\section{Limitations and benefits of chemical tests}

Chemical (presumptive) tests have been employed for many years and still play an important role when attempting to locate an area of interest for further forensic examination and/or DNA analysis. Comprehensive reports of their performance and specificity are available., ${ }^{2,67}$ These chemical tests are not human specific and in general are applied sequentially when a mixed body fluid may be present. Many rely on the properties of enzymes in body fluids and many of the reagents are destructive to the samples and/or inhibit downstream processes. ${ }^{7}$

Nonvisible stains or stains on dark surfaces are difficult to locate in situ and have been visualized with light sources that use the autofluorescence shown by some body fluids. ${ }^{89}$ Variability between body fluids and different surfaces can affect the usefulness of these methods, and exposure to such light sources may cause damage to the DNA in the stain. The very sensitive luminol test is used in the dark to locate blood, but gives false positives with a wide range of chemicals and dilutes any stain that may be required for further analysis. ${ }^{10,11}$

\section{Limitations and benefits of tests based on antibody-antigen interactions}

Body fluid identification using immunochromatographic- and enzyme-linked immunosorbent assay (ELISA)-based methods offers a high degree of specificity and sensitivity. ${ }^{12-14}$ These tests identify the presence of the relevant antigen rather than the activity of the antigen. Environmental factors can affect the antigen-antibody interaction leading to false positives or negatives, and all of these tests are affected by the high-dose hook effect. These tests are not used to localize areas of staining or in a sequential way, and in each of these tests, a portion of the sample is removed and solubilized prior to testing.

\section{Blood}

Chemical tests for blood are sensitive but lack specificity, generally relying on the catalytic activity of heme groups present in hemoglobin, and false positives with oxidants including plant peroxidases can occur. ${ }^{2,7,15}$ Tests include leucomalachite green, one of the least sensitive but more specific tests; tetramethylbenzidine, the active component of Hemastix $^{\circledR}$ (Bayer AG, Leverkusen, Germany); ortho-tolidine, the active component of Combur ${ }^{\circledR}$ test strips (Roche Diagnostics Ltd, Basel, Switzerland); and phenolphthalein (Kastle-Meyer test), a sensitive test with high specificity. ${ }^{6,10,15}$ Confirmatory but often impractical tests include microscopic identification of red and white blood cells and crystal tests in which the crystals of hemochromogen (Takayama) or hematin (Teichman) are formed confirming the presence of blood. ${ }^{6}$

The ABAcard ${ }^{\circledR}$ Hematrace $^{\circledR}$ (Abacus Diagnostics ${ }^{\circledR}$, West Hills, CA, USA) and the SERATEC ${ }^{\circledR}$ HemDirect (SERATEC ${ }^{\circledR}$ $\mathrm{GmbH}$, Göttingen, Germany) tests are based on monoclonal antihuman hemoglobin antibodies that cross react with the blood of primates and mustelidae, likely due to a common amino acid sequence in the alpha chain of hemoglobin. ${ }^{16,17}$ The RSID ${ }^{\text {TM}}$-blood test (Independent Forensics, Hillside, IL, USA) detects glycophorin A, a protein expressed abundantly and specifically in red blood cell membranes, with no cross reactivity observed to date. ${ }^{18}$

\section{Saliva}

The Phadebas ${ }^{\circledR}$ test (Magel Life Sciences, Lund, Sweden) ${ }^{19}$ is the common presumptive test used to determine the presence of saliva and is based on the detection of $\alpha$-amylase. The test is not confirmatory for the presence of human saliva as small amounts of the $\alpha$-amylase enzyme are known to be present, as salivary and pancreatic forms, in other body fluids including breast milk, sweat, semen, vaginal fluid, feces, and in other mammals. ${ }^{20-22}$ An alternative colorimetric test for saliva, which has also proved to be a useful localization reagent more sensitive than the Phadebas ${ }^{\circledR}$ test, is the $\mathrm{SALIgAE}^{\circledR}$ test from Abacus Diagnostics (West Hills, CA, USA). ${ }^{23,24}$

The RSID ${ }^{\text {TM}_{-}}$-saliva test is based on antihuman salivary anti-amylase antibodies. ${ }^{25}$ False positives have been observed with rat saliva, breast milk, neat urine, feces, and semen sample. This test was found to be a more sensitive and specific test than both the Phadebas ${ }^{\circledR}$ and the SALIgAE ${ }^{\circledR}$ tests. ${ }^{14,23}$

\section{Semen}

In the absence of the microscopic identification of spermatozoa, semen is typically located using the presumptive test that detects seminal acid phosphatase, an enzyme secreted by the prostate gland, but this is not unique to the seminal fluid. . $^{62}$ This test is most often performed using Brentamine Fast Blue reagent, although other alternatives exist. ${ }^{6}$ Although 
not widely used any longer, confirmatory crystal tests are available for detecting semen, including the Florence test that is based on the formation of choline crystals. ${ }^{6}$

The glycoprotein, prostate-specific antigen (PSA also known as $P 30$ and kallikrein 3), has been used to identify semen for some time. ${ }^{6,27}$ Common methods that are currently used include immunological tests such as SERATEC ${ }^{\circledR}$ PSA semiquant test, ABAcard ${ }^{\circledR}$ p30, and Biosign ${ }^{\circledR}$ PSA test (Princeton BioMeditech Corporation, Princeton, NJ, USA), although false-positive reactions to urine, vaginal fluids, breast milk, and semen-free postmortem rectal swabs have been observed. ${ }^{27-29}$

Semenogelin has also been used to detect semen using immunochromatographic tests. ${ }^{30-32}$ The RSID ${ }^{\text {TM }}$-Semen test was found to be less sensitive in comparative studies with ABAcard $^{\circledR}$ p30 and SERATEC ${ }^{\circledR}$ PSA, and there are reports of kit components giving false positive results. ${ }^{33}$

\section{Vaginal secretions and menstrual blood}

Menstrual blood and vaginal secretions are fluids of mixed composition for which identification has proved difficult. Lugol's staining of the glycogen-containing squamous epithelial cells of the vaginal wall, the microscopic identification of endometrial cells, and the detection of lactate dehydrogenase isoenzymes 4 and 5 are now considered not to be specific for vaginal cells. ${ }^{34,35}$

Immunochromatography tests for D-dimer, a soluble fibrin degradation product detected clinically for the diagnosis of thrombosis, is recognized as a possible test for menstrual blood. ${ }^{36,37}$ An alternative approach using ELISA targeting $M M P 14$, estrogen receptor $\alpha$, and fibrinogen was used to differentiate between peripheral and menstrual blood, although no other body fluids were tested for cross reactivity. ${ }^{38}$

\section{Urine}

Localization of urine stains is difficult as they are typically diffuse, pale, and spread over large areas. Presumptive tests are typically based on the detection of urea, urease, or uric acid. These tests are not specific, as sweat and other substances containing high amounts of urea also react positively. ${ }^{6,39}$ Tests for creatinine have also been used to detect urine. ${ }^{6}$

The detection of Tamm-Horsfall glycoprotein protein $(T M P)$, which is also present in the urine of animals, has been reported previously and incorporated into the RSID ${ }^{\mathrm{TM}}$-Urine test. TMP appears to be suitable as a specific test for urine although the presence of vaginal fluid can inhibit the result of the test and the presence of blood in the sample can make the test difficult to read. ${ }^{12}$

\section{Sweat}

To date, there is no practical screening test for identifying sweat. Although DNA is frequently recovered and profiled from areas of clothing likely to contain sweat, little research has been undertaken. ELISA-based assays have been developed for the detection of sweat-specific protein $G-81$ and dermicidin but have not been widely adopted..$^{40,41}$

\section{Identification of new (protein) markers}

ELISA and immunochromatographic tests rely on the discovery and characterization of specific markers. Twodimensional, high-performance liquid chromatography, mass spectrometry (MS), and quadrupole time-of-flight MS have each been used to produce proteomic profiles characteristic of each of six key forensic body fluids (blood, menstrual blood, saliva, semen, vaginal material, and skin) and identify new candidates such as osteopontin and uromodulin to detect urine. ${ }^{42}$ Other markers such as statherin (saliva) and semenogelin 1 and 2 (semen) are used for mRNA testing (see the following section).

\section{RNA- and DNA-based technologies}

RNA and DNA are increasingly utilized in a variety of novel forensic applications such as: to identify body fluid, to quantify RNA degradation for estimating postmortem interval and the age of stains, to estimate the age of wounds by monitoring reactive changes in gene expression, and to determine the cause of death. ${ }^{3,4,5,43-46}$ Such methods include the use of mRNA, miRNA, specific DNA methylation patterns, and characterization of body fluid--specific microbial communities.

\section{mRNA-based methods}

Body fluids of interest typically contain multiple cell types, each expressing a characteristic pattern of mRNA transcripts. Harnessing these multicellular transcriptomes is the basis for the development and implementation of mRNA profiling in forensic work.

mRNA is now widely recognized to be stable in body fluids dried on a variety of surfaces and can be recovered in sufficient quality and quantity for analysis from many sample types. ${ }^{47-52}$ An advantage of mRNA profiling is that RNA recovery from stains can be integrated into a typical DNA profiling workflow with a number of different RNA extraction methods having been described. ${ }^{52-56}$ Comparison of different commercial RNA extraction methods showed different success rates in terms of yields and DNA and RNA profiling, with no one option being better than the 
other; this finding has been supported by collaborative trials. ${ }^{56-59}$

The ability to identify an mRNA transcript of interest is related to the abundance of transcript and stability of each transcript in the cell with alternative markers for the same body fluid exhibiting different sensitivities. ${ }^{53,57-63} \mathrm{mRNA}$ profiling is comparable in sensitivity to presumptive tests where such comparisons have been made. ${ }^{60}$

RNA profiling would be improved by the development of a reliable method for mRNA quantification; excess template results in target overamplification and increased risk of "nonspecific artifacts" ${ }^{60}$ Current options only measure the total nucleic acid or RNA and are not human specific; measurements are usually done by using techniques such as UV spectrometry, fluorometric assays using intercalating dyes, the Agilent 2100 Bioanalyzer, Nanodrop ND spectrophotometer, and Quant-iT ${ }^{\mathrm{TM}}$ RiboGreen ${ }^{\circledR}$ RNA kit. ${ }^{49,56,61,64}$

Reverse transcriptase polymerase chain reaction (RT-PCR) is a sensitive method capable of detecting low-abundance mRNA obtained from limited samples. ${ }^{50,53,61,65-68}$ The most widely implemented approach in casework is end-point RT-PCR coupled with capillary electrophoresis, enabling the detection of several body fluids simultaneously and thus minimizing sample use and contextual effects. This method was first developed by Juusola and Ballantyne in 2005 and subsequently by others. ${ }^{61-64,69-71}$

Quantitative RT-PCR (qRT-PCR) calculates the difference between the target transcript and a reference or housekeeping gene known as $\Delta \mathrm{CT} \cdot{ }^{53,67,68,72}$ An advantage of this very sensitive approach is that numerical thresholds can be established for reporting. A drawback is the current restriction on the dyes that can be used, limiting the number of markers that can be targeted in a single reaction. Improvements such as high-resolution melting analysis have been proposed to overcome this limitation. ${ }^{73}$ Results between end-point RT-PCR and qRT-PCR revealed that by using either of these methods, it is not yet possible to attribute the detected mRNA transcript abundance to a major or minor DNA component. ${ }^{59,74}$ Recently, new methods have emerged, such as real-time RT loop-mediated isothermal amplification, offering equal sensitivity and specificity but significantly simpler and quicker analyses. ${ }^{75}$

Constitutively expressed housekeeping genes provide a reference point and assess the performance of a reaction when using capillary electrophoresis-based methods and are essential when using quantitative methods. ${ }^{67,76}$ An ideal housekeeping gene is one that is expressed in all tissues, does not vary significantly amongst and within individuals, and is not affected significantly by physiological/pathological conditions. A number of housekeeping genes have been used in forensic studies, which include $G A P D H, A C T B, S 15, B 2 M$, $T E F, U C E, G 6 P D, U B C$, and $18 S$ RNA. ${ }^{53,58,61-63,68,70,76-78}$

RT-PCR can exhibit significant variation even between identical samples. This can be caused by a number of factors including differing secondary structure of RNA transcripts, stochastic variation when dealing with very small samples, and RNA quality and inhibition. Housekeeping genes are no exception and there is general agreement that their transcript abundance can vary between people and between fluids. ${ }^{61,70,79,80}$ For example, buccal cells and semen exhibit very low transcript abundance of housekeeping genes compared to the body fluid-specific genes, and it is likely that there is no one suitable housekeeping gene for all body fluids.

mRNA markers can be selected by a candidate gene approach where the gene function is generally known. ${ }^{61-64}$ The alternative is a discovery approach such as a comparative microarray-based analysis of multicellular transcriptomes or RNA sequencing (transcriptome) analysis. ${ }^{53,81,82}$ Candidate markers based on a body fluid-specific function, such as hemoglobin, are more likely to be expressed specifically. The most frequently proposed RNA markers for blood are generally divided into proteins associated with the erythrocyte membrane (such as ankyrin 1, glycophorin A, and betaspectrin) and proteins associated with hemoglobin and the heme biosynthesis pathway (such as alpha- and beta- hemoglobin, porphobilinogen deaminase, and amino-levulinate synthase 2). Some of these proteins (eg, glycophorin A) are used in the aforementioned immunological tests. The markers are considered specific, with reported non-specificity in tissues such as menstrual blood and saliva possibly due to trace amounts of blood. ${ }^{50,53,61,62,64,66,69,70,77,78,81}$

Markers for seminal fluid and spermatozoa include protamines - PRM1 and PRM2 - most widely used for the detection of spermatozoa, and transglutaminase 4 and semenogelin 1 and 2 for seminal fluid. Semenogelin is a substrate for $P S A / P 30 /$ kallikrein 3 which itself has been used by some. These markers are also specific showing little, if any, cross reactivity. ${ }^{50,61,62,64,66,69,70,72,78,81}$

Of the four classes of peptides that are secreted by the salivary glands into saliva, histatin and statherin are favored as RNA markers for saliva. Three of the proline-rich proteins comprise a large proportion of the total salivary peptides. Some keratins have also been used. ${ }^{53,61,62,64,66,68-70,78,81,83}$ The quantity and quality of these peptides and the full length 
and partially degraded $m R N A$ transcripts found in saliva are influenced by factors such as the time of day and age and health of the individual, and several authors have noted that there is high variation coupled with low amounts of RNA in saliva samples. ${ }^{61,66}$ Statherin has been reported to be present at high levels in nasal secretions and occasionally at lower levels in vaginal secretions, but histatin 3 appears to be specific for saliva. ${ }^{83}$

A particular problem is distinguishing between the stratified squamous epithelial cells found in the mouth, vagina, and skin, as they are structurally closely related. Since the functions of these cell types are similar (protection and secretion), finding measurable differences between them is challenging, particularly in nonkeratinized buccal and vaginal cells.

Vaginal fluid includes cells lining the vaginal wall, cervix, endometrium, and fallopian tubes and blood, all of which can vary with age and health conditions. Early candidates for vaginal markers, human beta-defensin 1 and mucin 4 , are not only consistently expressed in vaginal secretions but have also been detected by numerous authors to be present in saliva, nasal secretions, and sometimes semen. They may be better considered as mucosal markers. ${ }^{5,57,62,64,69,70,72,78,82,84}$ More recently, two further candidates have been identified using transcriptome profiling, CYP2B7P1 and $M Y O Z 1$, both of which appeared to be sensitive markers. No detectable cross reactivity was found for $C Y P 2 B 7 P 1$, although $M Y O Z 1$, a skeletal muscle protein found in the tongue, was detected in saliva. ${ }^{65}$ The microflora of the vagina has been exploited by several authors as an alternative tool to identify vaginal material and is described in the following text. ${ }^{85-89}$

Menstrual blood is also a complex fluid composed of varying amounts of circulatory blood, vaginal secretions, microbial communities, and cells associated with the menstrual cycle. It is the remodeling of the endometrium during menstruation that offers potential candidates for identification. Foremost amongst these are the $M M P 7$ and $M M P 11$, which have been widely studied by a number of groups. ${ }^{57,61,62,64,68-71,77}$ Expression of the $M M P$ genes has been found to vary throughout the course of a menstrual cycle. ${ }^{66}$ Marker transcript abundance for circulatory blood and vaginal secretions has been observed in menstrual blood samples, and low and inconsistent $M M P$ transcript abundance has sometimes been found in other fluids, such as blood, muscle, skin, semen, and saliva. ${ }^{59,69,70,77}$

The identification of skin cells present on an item from which a DNA profile can be obtained relies on identifying the differences between the mucosal epithelial cells (vaginal and buccal) and epidermal cells. A number of the cytokeratin families have been proposed for epidermal cell identification. Of these, $L C E 1 C$ and $L O R$ showed the most consistent detectable transcript abundance in skin samples with poor and inconsistent detection of other markers and housekeeping genes, likely reflecting the very low levels of mRNA in these cells. ${ }^{65,90}$ Some of these markers have been found to be highly expressed in vaginal secretions. ${ }^{65,91}$

Regardless of the technical approach used, reporting guidelines based on laboratory validation are needed. Proposed reporting strategies for end-point PCR approaches vary. They include weighted scoring systems based on the presence (peak height), absence, and specificity of multiple markers; consensus amplifications; multidimensional scaling approaches; and the controls used. ${ }^{59,69,70,71,78,92} \Delta \mathrm{CT}$ measurements (the difference in cycle threshold between the target and reference marker) are employed for quantitative PCR methods, although such methods may struggle to interpret mixed samples. ${ }^{5}$

Massively parallel sequencing (MPS) is gaining popularity in forensic science with the analysis of DNA and only recently has this methodology turned to RNA analysis. The analysis of mRNAs in body fluids using MPS has been investigated with promising results with sequencing blood, menstrual blood, saliva, and vaginal material, and the simultaneous sequencing of DNA and RNA from the same sample has been achieved..$^{93,94}$ Matrix-assisted laser desorption/ ionization time-of-flight mass spectroscopy, a fluorescence dye-free method with high specificity, has also been used for mRNA profiling to characterize the cDNA directly. ${ }^{78}$

\section{NanoString ${ }^{\circledR}$}

The NanoString ${ }^{\circledR}$ nCounter system is a platform that captures and counts individual mRNA transcripts and can quantify the expression of up to $800 \mathrm{mRNA}$ candidates in a single reaction using color-coded molecular barcodes..$^{95,96}$ The NanoString ${ }^{\circledR}$ technology has recently been investigated as a method of body fluid identification using mRNA for forensic purposes. The first study used 18 body fluid-specific mRNAs and two endogenous controls. Total RNA was used in the analysis and the counts were normalized against the housekeeping gene $G A P D H$. Blood and semen were accurately identified using the body fluid-specific markers; however, the vaginal and saliva mRNA markers used were not specific. ${ }^{97}$

In another study, 23 mRNA markers and ten housekeeping genes were tested against a wide range of samples including total RNA isolated from body fluids that had been stored in different conditions and using direct cell lysates. ${ }^{98}$ Using an algorithm and calculating the maximum likelihood estimates, 
samples of single sources of blood, semen, vaginal secretions, menstrual blood, and skin all demonstrated the expected body fluid-specific gene expression for at least two of the chosen mRNA biomarkers. Once again, saliva samples were problematic using this technology. The technology has potential in forensic science as many markers can be multiplexed, but as for mRNA profiling, further improvements in saliva and vaginal fluid detection are required.

\section{miRNAs}

miRNAs are a class of small RNA molecules that have the potential to be an alternative option to mRNA for body fluid identification. Mature miRNAs are 18-25 nucleotides in length and are involved in the regulation of mRNA translation and stability. ${ }^{99}$ Currently, the miRNA database has $\sim 29,000$ entries of which 1,881 are annotated as human. ${ }^{100}$ miRNAs have been shown to be exceptionally stable postmortem and can be successfully isolated from forensically relevant samples. ${ }^{101-108}$ Some are human specific. A single miRNA may have multiple mRNA targets and any given target may have multiple miRNAs; therefore, a key limitation is their specificity, for both body fluid and species.

Using differing methods, various studies have proposed a number of miRNAs as being specific for body fluids. ${ }^{101-108}$ Common to these approaches is the use of qPCR to confirm specificity. When the results of these studies were compared, from a total of nine markers identified for peripheral blood, only two, miR-16 and miR-451, were identified in more than one study. Of the eight markers identified in three studies of semen, only miR-135b and miR-10b, which are closely related to miR-135a and miR-10a, were in agreement. ${ }^{102,103}$

While miRNA markers specific for saliva were discovered in all studies, the specificity of miRNA-658 and miR205 proposed by one study was unable to be replicated by another. ${ }^{102,106}$ The explanation given for these results was that miR-658 may have unstable expression in body fluids (possibly caused by physiological conditions) and that miR-205 may be epithelium-specific and may not be able to distinguish vaginal and oral epithelia. Further, two markers, miR-223 and miR-145, have also been proposed for saliva, but not corroborated by others to date. ${ }^{104}$ Markers have also been proposed for vaginal secretions - miR-124a, miR-372, miR-1260b, and miR-654p. ${ }^{102,104}$

Other studies have focused on blood and saliva miRNAs, such as for the simultaneous analysis of DNA and miRNAs (for studying mixed body fluid stains) and for further body fluid-specific miRNA discovery. ${ }^{105,107,108}$
Reference small RNAs have been identified for both body fluid (miRNU24, RNU43, and RNU66) and organ identification (SNORD24, SNORD38B, and SNORD43). ${ }^{109,110}$

\section{DNA-compatible cell-specific identification}

An alternative approach to body fluid identification is to identify individual cells by specifically labeling the cells at the protein, DNA, or RNA level coupled with microscopy. Immunohistochemistry has been evaluated as a way to identify epidermal cells and distinguish the vaginal and oral mucosal epithelial cells using cytokeratins..$^{90,111}$ Cells of mucosal origin could be distinguished from epidermal cells when compared directly, although low-level expression of each cytokeratin was found in the other cell type.

In a different approach, immunofluorescence was proposed for the detection of human blood in situ using fluorescently labeled antihuman antibodies to detect erythrocytes (glycophorin A) and nucleated leukocytes (CD45, myeloperoxidase, histone 1), although the application of several wash steps may make this method impractical for casework application. ${ }^{12} \mathrm{XY}$ fluorescent in situ hybridization (FISH) coupled with laser microdissection (LMD) and DNA profiling at standard and low copy number conditions has been shown to be an effective way to obtain DNA profiling information from individual cell groups identified using specific fluorescent labeling techniques, in this case the $\mathrm{X}$ and $\mathrm{Y}$ chromosomes. ${ }^{113}$

Detection of ESR1 (estrogen receptor 1) using fluorescently labeled monoclonal antibodies showed that buccal and vaginal epithelial cells were able to be distinguished using this marker when mRNA profiling could not. This shows that mRNA expression and protein expression in tissues do not always correlate. ${ }^{114}$ FISH of the RNA suspension has been used to identify and locate the epithelial cells using a fluorescently labeled LNA probe for keratin 10; epithelial cells were subsequently isolated using LMD and were DNA profiled. ${ }^{115}$ Although such labeling techniques may prove to be specific, prolonged time required to selectively collect the labeled cells by LMD emphasizes that such techniques are likely to be restricted to targeted cases rather than for general applications.

\section{Epigenetic approaches}

A body fluid identification method that detects cell-/tissuespecific features of DNA would be useful as the cell type and the short tandem repeat (STR) DNA profile would come from the same DNA source, and attributing a body fluid to a 
particular DNA profile may be possible. DNA methylation, an epigenetic modification that occurs at the $5^{\prime}$ position of cytosine in a $\mathrm{CpG}$ dinucleotide, has been explored for body fluid identification as epigenetic differences are found between body fluids of forensic interest such as blood, semen, saliva, skin, urine, and vaginal secretions. ${ }^{116-123}$

The predominant methods for detecting methylation are either the use of a methylation-sensitive/dependent restriction enzyme followed by PCR or bisulfite sequencing or a combination of both. In the former, comparison of the peak heights of amplified loci following methylation-sensitive/ dependent restriction enabled body fluid identification. ${ }^{116}$ Low-level samples and samples with incomplete restriction, inhibition, excess template, and degradation of the template can distort the methylation ratios and compromise the results, but advantages of this method include a level of sensitivity comparable to DNA profiling and coanalysis with STR amplification.

In a different approach, the Illumina Human Methylation bead array system was used to screen over $450,000 \mathrm{CpG}$ sites using DNA from samples of blood, saliva, and vaginal fluid to identify possible markers. ${ }^{119}$ Pyrosequencing was then used to evaluate candidate markers further in samples of blood, saliva, and vaginal fluid, with successful markers showing high specificity and sensitivity for their target body fluids.

A number of markers have emerged as suitable for further evaluation. The markers DACT1 and USP49 showed spermatozoa (not seminal fluid) specific hypomethylation and were considered suitable for identifying spermatozoa. ${ }^{120}$ PFN3 appeared to be a reliable marker for vaginal fluid showing significant hypomethlyation in these samples. Using multiplexes combining DACT1, USP49, PFN3, and PRMT2, semen containing spermatozoa could be successfully identified and menstrual blood and vaginal fluids could be differentiated from blood and saliva, and similar differentiation of semen was achieved by others using a different multiplex of markers. ${ }^{118,121}$

Examples of cross reactivity of body tissue-specific markers in other body fluids including those from male donors and difficulties in interpreting the results from menstrual blood samples have been reported. ${ }^{122}$

A DNA methylation assay, Nucleix DSI-Semen ${ }^{\mathrm{TM}}$, is now available and uses methylation-sensitive/dependent enzyme restriction followed by amplification with locus-specific markers to identify semen. ${ }^{124}$ Peak heights of the amplified markers, including controls indicating complete digestion and amplification, are used to determine if the results indicate the presence of semen, not semen, or are inconclusive.
Samples of semen mixed with other body fluids can return an inconclusive result, though no false positive reactions were obtained.

Natural variation in methylation status has been found between individuals, and some tissue-specific differentially methylated regions are susceptible to change due to environmental factors and age. ${ }^{11,125}$ For example, methylation of a CpG site in PRMT2 in blood samples was found to be an age-associated marker, whereas no significant difference based on age was observed for three spermatozoa-specific hypomethylated markers DACT1, USP49, and PRMT2 in men of different ages. ${ }^{116,118}$

Initially promising, the detection of specific DNA methylation patterns in different body fluids is still in its developing stage and it is unclear whether this approach has been implemented into casework. New approaches combining epigenetic analysis and MPS for body fluid identification are appearing in the literature and may provide a fresh impetus for discovering stable markers that do not change with influences such as age and environment. ${ }^{126}$

\section{Microbial community profiling}

Microbes, bacteria, fungi, and viruses are well established in and on the human body, and the human microbiome is a focus of much study. ${ }^{127}$ The microbial communities of the mouth and nose, feces, skin, and vagina are some examples. Different locations in and on the body have characteristic microbial communities, and even though these communities may vary between individuals, within the same individual and with age and ill health, there are sufficient similarities in forensically relevant body fluids/tissues for this approach to provide promise for identification. ${ }^{128-131}$

The microflora of the vagina has been exploited by several authors as a tool to identify vaginal material. ${ }^{85-88} \mathrm{~A}$ healthy human vagina is dominated by lactobacilli, and typically Lactobacillus crispatus, L. gasseri, L. jensenii, and/or L. iners are found in women. Usually one species predominates; for example, L. crispatus is prevalent among women in North America, Europe, and Asia. ${ }^{132}$ Not all women have all species of lactobacilli all of the time, and levels of lactobacilli are reduced in women under 20 years and are unlikely to be present in prepubescent children. ${ }^{133}$

Using either amplification of the nonconserved regions of the Streptococcus-specific glucosyltransferase genes or amplification of ribosomal RNA genes, detection of oral Streptococcus species was successful in forensic-like samples proposing the identification of these bacteria as useful in the identification of saliva. ${ }^{134,135}$ This was extended 
to the analysis of oral microbial communities in expirated blood on a variety of surfaces for extended periods of time after deposition. ${ }^{136}$

Successful and specific microbial signatures have been obtained from the microbial communities of vagina, oral cavity, and feces using multiplex real-time PCR amplification and primers specific for L. crispatus and L. gasseri (vagina), Streptococcus salivarius and Streptococcus mutans (saliva), and Enterococcus species (feces). ${ }^{87,89}$ The microbial community of feces is also unique with Bacteroides vulgaris, B. uniformis, and B. thetaoitaomicron being predominant in the fecal samples. ${ }^{137}$

A multiplex method - which involves combining epigenetic markers for semen and vaginal fluid, and bacterial markers for saliva and vaginal bacteria - has been successfully used to distinguish between blood, semen, saliva, vaginal secretions, and menstrual blood. ${ }^{138}$

Bacterial communities are also known to be present on the skin with as many as 150 unique species-level bacterial phylotypes being identified in a pyrosequencing study of $16 \mathrm{~S}$ ribosomal RNA genes. Both inter- and intra-person variations in the species were detected, although a core group of bacteria were typically present including Lactobacillus, Streptococcus, and Staphylococcus species. ${ }^{139}$ This work was extended to investigate whether by comparing the bacterial communities on handled surfaces and items, the bacterial community profiling was sufficiently discriminating to link individuals to the items they touched. This was not always found to be the case. ${ }^{140}$

Bacterial community profiling must take into account the possibility of bacteria being naturally present in samples. For example, L. crispatus and L. gasseri have been detected in yoghurt, and a small number of saliva and semen samples were found to test positive for L. gasseri. ${ }^{70,87}$ In a comprehensive search for candidates for vaginal flora identification, the more commonly used bacteria for vaginal secretion identification, L. crispatus, L. gasseri, L. jensenii, and L. iners, were found on other areas of the body, for example, the hands and the groin. ${ }^{141}$ Bacteroides species are not human specific and have been found occasionally in vaginal samples, possibly as a result of crosscontamination during sampling or from natural contamination of the vaginal tract. ${ }^{135}$ Small amounts of $S$. salivarius, S. mutans, and $L$. gasseri have also been found in feces. ${ }^{87}$

\section{Spectroscopic tests}

\section{Raman spectroscopy}

Raman spectroscopy has been evaluated for a variety of applications in forensic science and has long been recognized as suitable for the analysis of biological materials. ${ }^{2,142}$
Raman spectroscopy is a nondestructive test that relies upon the scattering of low-intensity laser light by compounds including biological materials. The resultant spectra are complex and require advanced statistical treatments to build a unique spectroscopic signature of the molecular structure of each fluid. This complexity is in part because dry body fluids are heterogeneous and there is additional variation between individuals. Unique Raman spectroscopic signatures have been determined for blood, semen, vaginal fluid, saliva, and sweat that correspond to the components in the respective body fluids (such as hemoglobin in blood and spermine in semen). ${ }^{2,143-146}$ These signatures can be used for comparison with unknown samples and can potentially discriminate human and animal blood traces. ${ }^{147}$

Although not as sensitive as fluorescence spectroscopy, Raman spectroscopy is considered more selective and specific and has been used to identify blood in the presence of contaminating compounds with varying success, on tiny particles of blood on adhesive tape lifts, in mixtures of blood and semen, and on common surfaces. ${ }^{148-150}$

\section{Fourier transform infrared spectroscopy}

Fourier transform infrared (FT-IR) spectroscopy is routinely used in forensic chemistry to analyze drugs, chemicals, fibers, and paints with unique and characteristic spectral signatures determined for each sample. Although being used widely in medical science to differentiate biological molecules, it has only recently been considered for the forensic analysis of biological material. ${ }^{151}$ A current limitation of spectrophotometric methods is that they are typically evaluated using fresh body fluids in reasonable quantities on straightforward surfaces with little if any dirt, debris, or other associated environmental contamination. In a recent study, attenuated total reflectance FT-IR has been proposed as a method for the unique and nondestructive identification of body fluids. ${ }^{151}$ The dominant FT-IR spectral components of blood were found to correspond to human serum albumin and hemoglobin. Lysozyme and $\alpha$-amylase were identified as the major components of the spectra from dried saliva and acid phosphatase and albumin were the dominant components of semen. The findings for vaginal secretions were of particular interest. As lysozyme and acid phosphatase have been detected in vaginal fluids using other tests, the spectra of these molecules were specifically compared with those developed from vaginal secretions. The spectra were similar but exhibited sufficient differences in shape that all body fluids tested could be distinguished. 


\section{Mass spectrometry}

MS is commonly associated with the detection of drugs and analytes in forensic science and has been used previously in forensic genetic research for single nucleotide polymorphism analysis, STR typing, DNA/RNA sequencing, and cDNA analysis..$^{78,152-154}$ MS measures the mass of molecules at high resolution. For example, the sequence of multiple fragments of each protein in a sample can be determined and the combination of proteins characteristic of each fluid can be identified, yielding a sensitive and specific test.

Recently, MS has been evaluated for body fluid identification for forensic purposes. Using a combination of methods, the proteomes of menstrual blood, blood, semen, and saliva were investigated and unique proteins identified for each fluid. These included histones, ribosomal proteins, cytokines, and $M M P s$, favored by the mRNA community for menstrual blood. ${ }^{155,156}$ Alpha- and beta-hemoglobin, spectrin, and solute carrier family 4 (anion exchanger), member 10 were proposed for blood; $\alpha$ amylase 1 , histatin 1 , and cystatin SA for saliva; and semenogelins 1 and 2, prostatic acid phosphatase, MUC6, and others for semen.

\section{Nuclear magnetic resonance spectroscopy}

Nuclear magnetic resonance (NMR) spectroscopy is an alternative approach to mass spectrometry but may not be easily accessible to forensic laboratories. ${ }^{157}$ The unique metabolite composition of each body fluid yielded a signature spectrum that combined with statistical analysis was used to identify each body fluid. Using a series of complex statistical and mathematical processes, a representative NMR profile was produced for each body fluid which accounted for the variability between donors. Again, these profiles can be compared to samples of unknown origin for identification and mixtures can be determined at least qualitatively. ${ }^{157}$

\section{Fluorescence spectroscopy}

Fluorescence spectroscopy is based on the absorption of radiation by a fluorophore in the sample and its subsequent emission at a longer wavelength, the general principle being that different body fluids contain different components that will have characteristic fluorescent signatures. ${ }^{158,159}$ Generally, the methods are impractical, can be adversely affected by environmental factors, and are not widely used, although micro-spectrophotometry was compared with Raman spectroscopy as a tool to identify microscopic specks of blood on tape lifts of items. Both methods were comparably specific and sensitive. ${ }^{149}$

\section{Biosensors}

Quantum dots are recognized as an ideal medium for targeted and specific detection of molecules in many applications. The ability to conjugate functional groups such as antibodies and oligonucleotides has been recognized and there is an extensive array of sensing options including colorimetry and fluorescence. ${ }^{160,161}$ However, this type of biosensor has not been widely studied for application in forensic science despite the specificity and sensitivity. A recent example of the use of such immunofluorescent biosensors for forensic applications has shown great promise. ${ }^{162}$ In this study, antiglycophorin A was conjugated to fluorescent semiconductor quantum dots. When mixed with liquid blood, the characteristic fluorescence emission spectra were quenched or altered in a concentration-dependent manner. Subsequent DNA profiling of samples treated with the quantum dots was unaffected.

\section{Conclusion}

Body fluid identification is an important aspect in criminal investigations and as advancements in technology have improved, the ability to detect and identify body fluids has also improved. At the crime scene, quick and easy-to-use presumptive tests have been used to locate and indicate the body fluid of interest, with confirmatory testing being available in the laboratory and recently in the field. However, with the advent of on-site DNA testing equipment such as the RapidHIT ${ }^{\circledR}$ system (IntegenX, Pleasanton, CA, USA) for case samples, there is an increasing need for sensitive and specific, nondestructive tests for use prior to DNA testing in the field. ${ }^{163}$ With future development of portable spectrometers and interpretation software, an approach such as Raman spectroscopy offers alternative solutions.

Laboratory-based methods developed recently have centered on molecular biology techniques such as mRNA and miRNA profiling and epigenetic approaches. Although their sensitivity and relative ease of use are recognized, there are challenges in selecting appropriately specific markers. This can be problematic when the sample is a mixture of body fluids with one or more at a low amount relative to the other. Distinguishing these low-level components from low levels of nonspecific expression, if present, is more challenging and must be addressed with clear reporting and interpretation guidelines. Great promise is shown by recent research using quantum dots as a sensitive, specific approach to immunological testing, with the added advantage of being compatible with subsequent DNA profiling processes. The accessibility of MPS and proteomic tools will continue to 
enable the development and subsequent adoption of new body fluid identification methods into the future.

\section{Acknowledgments}

The authors wish to thank Dr DA Elliot and Dr M-H Lin for their helpful comments on the manuscript.

\section{Author contributions}

Both authors were responsible for drafting, revising, and approving the article and are equally accountable for its content.

\section{Disclosure}

The authors report no conflicts of interest in this work.

\section{References}

1. Butler J. Advanced Topics in Forensic DNA Typing: Methodology. Waltham, MA: Academic Press; 2012.

2. Virkler K, Lednev IK. Analysis of body fluids for forensic purposes: from laboratory testing to non-destructive rapid confirmatory identification at a crime scene. Forensic Sci Int. 2009;188:1-17.

3. Silva SS, Lopes C, Teixeira AL, de Sousa MC, Medeiros R. Forensic miRNA: potential biomarker for body fluids? Forensic Sci Int Genet. 2015;14:1-10.

4. Vidaki A, Daniel B, Syndercombe-Court D. Forensic DNA methylation profiling - potential opportunities and challenges. Forensic Sci Int Genet. 2013;7:499-507.

5. Sijen T. Molecular approaches for forensic cell type identification: on mRNA, miRNA, DNA methylation and microbial markers. Forensic Sci Int Genet. 2015;18:21-32.

6. Gaensslen RE. Sourcebook in Forensic Serology, Immunology and Biochemistry. Washington, DC: US Department of Justice; 1983.

7. Tobe SS, Watson N, Daeid NN. Evaluation of six presumptive tests for blood, their specificity, sensitivity, and effect on high molecular-weight DNA. J Forensic Sci. 2007;52:102-109.

8. Kobus HJ, Silenieks E, Scharnberg J. Improving the effectiveness of fluorescence for the detection of seminal stains on fabrics. $J$ Forensic Sci. 2002;47:819-823.

9. Vandenberg N, van Oorshot RAH. The use of Polilight in the detection of seminal fluid, saliva and bloodstains and comparison with conventional chemical based screening tests. J Forensic Sci. 2006;51: 361-370.

10. Webb JL, Creamer TI, Quickenden TI. A comparison of the presumptive luminol test for blood with four non-chemiluminescent forensic techniques. J Forensic Sci. 2006;51:361-370.

11. Quinones I, Sheppard D, Harbison SA, Elliot DA. Comparative analysis of luminol formulations. Can Soc Forensic Sci. 2006;40: $53-63$.

12. Akutsu T, Watanabe K, Sakurada K. Specificity, sensitivity, and operability of RSID ${ }^{\mathrm{TM}}$-Urine for forensic identification of urine: comparison with ELISA for Tamm-Horsfall protein. J Forensic Sci. 2012;57: $1570-1573$.

13. Simich JP, Morris SL, Klick RL, et al. Validation of the use of a commercially available kit for the identification of prostate specific antigen (PSA) in semen stains. J Forensic Sci. 1999;44:1229-1231.

14. Casey DG, Price J. The sensitivity and specificity of the RSID ${ }^{\mathrm{TM}}$ saliva kit for the detection of human salivary amylase in the forensic science laboratory, Dublin, Ireland. Forensic Sci Int. 2010; 194:67-71.

15. Cox M. A study of the sensitivity and specificity of four presumptive tests for blood. J Forensic Sci. 1991;36:1503-1511.
16. Misencik A, Laux DL. Validation study of the Seratec HemDirect hemoglobin assay for the forensic identification of human blood. MAFS Newslett. 2007;36:18-26.

17. Johnston S, Newman J, Frappier R. Validation study of the Abacus Diagnostics ABAcard ${ }^{\circledR}$ Hematrace $^{\circledR}$ membrane test for the forensic identification of human blood. Can Soc Forensic Sci J. 2003;36: 173-183.

18. Schweers BA, Old J, Boonlayangoor PW, Reich KA. Developmental validation of a novel lateral flow strip test for rapid identification of human blood (Rapid Stain Identification ${ }^{\mathrm{TM}}$-Blood). Forensic Sci Int Genet. 2008;2:243-247.

19. Willott GM. An improved test for the detection of salivary-amylase in stains. J. Forensic Sci Soc. 1974;14:341-344.

20. Kipps AE, Whitehead PN. The significance of amylase in forensic investigations of body fluids. Forensic Sci. 6;1975:137-144.

21. Auvdel ML. Amylase levels in semen and saliva stains. J Forensic Sci. 1986;31:426-431

22. Keating SM, Higgs DF. The detection of amylase on swabs from sexual assault cases. J Forensic Sci Soc. 1994;34:89-93.

23. Pang BCM, Cheung BKK. Applicability of two commercially available kits for forensic identification of saliva stains. J Forensic Sci. 2008;53:1117-1122.

24. Liang T, Roy R. Ultraviolet-visible spectrophotometry (UV-VIS) and SALIgAE ${ }^{\circledR}$ qualitative and semi-quantitative tools for the analysis of salivary amylase. J Forensic Res. 2014;5:247.

25. Old JB, Schweers BA, Boonlayangoor PW, Reich KA. Developmental validation of RSID ${ }^{\mathrm{TM}}$-saliva: a lateral flow immunochromatographic strip test for the forensic detection of saliva. J Forensic Sci. 2009;54:866-873.

26. Kind SS. The use of the acid phosphatase test in searching for seminal stains. J Crim Law Criminol Police Sci. 1957;47:597-600.

27. Graves HCB. Non prostatic sources of protein-specific antigen: a steroid hormone dependent phenomenon? Clin Chem. 1995;41:7-9.

28. Yu H, Diamandis EP. Prostate specific antigen in milk of lactating women. Clin Chem. 1995;41:54-58.

29. Lunetta P, Sippel H. Positive prostate-specific antigen (PSA) reaction in post mortem rectal swabs: a cautionary note. J Forensic Leg Med. 2009;16:397-399.

30. Sato I, Kojima K, Yamasaki T, et al. Rapid detection of semenogelin by one step immunochromatographic assay for semen identification. J Immunol Methods. 2004;287:137-145.

31. Pang BCM, Cheung BKK. Identification of human semenogelin in membrane strip test as an alternative method for the detection of semen. Forensic Sci Int. 2007;169:27-31.

32. Old JB, Schweers BA, Boonlayangoor PW, Reich KA. Developmental validation of RSID-semen: a lateral flow immunochromatography strip test for the forensic identification of semen. J Forensic Sci. 2012;57:489-499.

33. Boward ES, Wilson SL. A comparison of ABAcard ${ }^{\circledR}$ p30 and RSID ${ }^{\text {TM}}$ semen test kits for forensic semen identification. J Forensic Leg Med. 2013;20:1126-1130.

34. Jones EL Jr, Leon JA. Lugol's test re-examined again: buccal cells. J Forensic Sci. 2004;49:64-67.

35. Stombaugh PM, Kearney JJ. Factors affecting the use of lactate dehydrogenase as a means of bloodstain differentiation. J Forensic Sci. 1987;23:94-105.

36. Baker DJ, Grimes EA, Hopwood AJ. D-dimer assays for the identification of menstrual blood. Forensic Sci Int. 2011;212:210-214.

37. Holtkoetter H, Dierig L, Schuerenkamp M, Sibbing U, Pfeiffer H, Vennemann M. Validation of an immunochromatographic D-dimer test to presumptively identify menstrual fluid in forensic exhibits. Int J Legal Med. 2015;129:37-41.

38. Gray D, Frascione N, Daniel B. Development of an immunoassay for the differentiation of menstrual blood from peripheral blood. Forensic Sci Int. 2012;220:12-18.

39. Huang CT, Chen ML, Huang LL, Mao IF. Uric acid and urea in human sweat. Chinese J Physiol. 2002;45:109-115. 
40. Sagawa K, Kimura A, Saito Y, et al. Production and characterisation of a monoclonal antibody for sweat-specific protein and its application for sweat identification. Int J Leg Med. 2003;117:90-95.

41. Sakurada K, Akutsu T, Fukushima H, Watanabe K, Yoshino M. Detection of dermicidin for sweat identification by real time RT PCR and ELISA. Forensic Sci Int. 2010;194:80-84.

42. Legg KM, Powell R, Reisdorph N, Reisdorph R, Danielson PB. Discovery of highly specific protein markers for the identification of biological stains. Electrophoresis. 2014;35:3069-3078.

43. Bauer M, Gramlich I, Polzin S, Patzelt D. Quantification of mRNA degradation as possible indicator of postmortem interval - a pilot study. Leg Med. 2003;5:220-227.

44. Anderson SE, Hobbs GR, Bishop CP. Multivariate analysis for estimating the age of a bloodstain. J Forensic Sci. 2010;56:186-193.

45. Cecchi R. Estimating wound age: looking into the future. Int $J$ Leg Med. 2010;124:523-536.

46. Palagummi S, Harbison SA, Fleming RI. A time-course analysis of mRNA expression during injury healing in human dermal injuries. Int J Leg Med. 2014;128:403-414.

47. Bauer M, Kraus A, Patzelt D. Detection of epithelial cells in dried bloodstains by reverse transcriptase polymerase chain reaction. J Forensic Sci. 1999;44:1232-1236.

48. Setzer M, Juusola J, Ballantyne J. Recovery and stability of RNA in vaginal swabs and blood, semen and saliva stains $J$ Forensic Sci. 2008;53:296-305.

49. Visser M, Zubakov D, Ballantyne KA, Kayser M. mRNA based skin identification for forensic applications. Int J Leg Med. 2011;125:253-263.

50. Kohlmeier F, Schneider PM. Successful RNA profiling of 23 year old blood stains. Forensic Sci Int Genet. 2012;6:274-276.

51. Fox A, Gittos M, Harbison SA, Fleming R, Wivell R. Exploring the recovery and detection of messenger RNA and DNA from enhanced fingermarks in blood. Sci Justice. 2014;54:192-198.

52. Alvarez M, Juusola J, Ballantyne J. An mRNA and DNA co-isolation method for forensic casework samples. Anal Biochem. 2004;335 289-298.

53. Zubakov D, Hanekamp E, Kokshoorn M, Van Ijcken W, Kayser M. Stable mRNA markers for identification of blood and saliva stains revealed from whole genome expression analysis of time-wise degraded samples. Int J Leg Med. 2008;122:135-142.

54. Bowden A, Fleming RI, Harbison SA. A method for DNA and RNA co-extraction for use on forensic samples using the Promega DNA IQ ${ }^{\mathrm{TM}}$ system. Forensic Sci Int Genet. 2011;5:64-68.

55. Akutsu T, Kitayama T, Watanabe K, Sakurada K. Comparison of automated and manual purification of total RNA for mRNA-based identification of body fluids. Forensic Sci Int Genet. 2015;14:11-17.

56. Grabmüller M, Madea B, Courts C. Comparative evaluation of different extraction and quantification methods for forensic RNA analysis. Forensic Sci Int Genet. 2015;16:195-202.

57. Haas C, Hanson E, Anjos MJ, et al. RNA/DNA co-analysis from human menstrual blood and vaginal secretion stains: results of a fourth and fifth collaborative EDNAP exercise. Forensic Sci Int Genet. 2014;8:203-212.

58. Haas C, Hanson E, Banemann R, et al. RNA/DNA co-analysis from human skin and contact traces - results of a sixth collaborative EDNAP exercise. Forensic Sci Int Genet. 2015;16:139-147.

59. Van den Berge M, Carracedo A, Gomes I, et al. A collaborative European exercise on mRNA-based body fluid/skin typing and interpretation of DNA and RNA results. Forensic Sci Int Genet. 2014;10:40-48.

60. Haas C, Hanson E, Kratzer A, Bar W, Ballantyne J. Selection of highly specific and sensitive mRNA biomarkers for the identification of blood. Forensic Sci Int Genet. 2011;5:449-458.

61. Fleming RI, Harbison SA. The development of an mRNA multiplex RT-PCR assay for the definitive identification of body fluids. Forensic Sci Int Genet. 2010;4:244-256.

62. Lindenbergh A, De Pagter M, Ramdayal G, et al. A multiplex (m)RNA profiling system for the forensic identification of body fluids and contact traces. Forensic Sci Int Genet. 2012;6:565-577.
63. Lindenbergh A, ven den Berge M, Oostra RJ, et al. Development of a mRNA profiling multiplex from the inference of organ tissues. Int $J$ Leg Med. 2013;127:891-900.

64. Juusola J, Ballantyne J. Multiplex mRNA profiling for the identification of body fluids. Forensic Sci Int. 2005;152:1-12.

65. Hanson E, Haas C, Jucker R, Ballantyne J. Specific and sensitive mRNA biomarkers for the identification of skin in "tough" DNA evidence. Forensic Sci Int Genet. 2012;6:548-558.

66. Haas C, Klesser B, Maake C, Bar W, Kratzer A. mRNA profiling for body fluid identification by reverse transcription endpoint PCR and real time PCR. Forensic Sci Int Genet. 2009;3:80-88.

67. Bustin SA. Absolute quantification of mRNA using real time reverse transcription polymerase chain reaction assays. $J$ Mol Endocrinol. 2000;25:169-193.

68. Juusola J, Ballantyne J. mRNA profiling for body fluid identification by multiplex quantitative RT-PCR. J Forensic Sci. 2007;52:1252-1262.

69. Richard ML, Harper KA, Craig RL, Onorato AJ, Robertson JM, Donfack J. Evaluation of mRNA marker specificity for the identification of five human body fluids by capillary electrophoresis. Forensic Sci Int Genet. 2012;6:452-460.

70. Roeder AD, Haas C. mRNA profiling using a minimum of five mRNA markers per body fluid and a novel scoring method for body fluid identification. Int J Leg Med. 2013;27:707-721.

71. Lindenbergh A, Maaskant P, Sijen T. Implementation of RNA profiling in forensic casework. Forensic Sci Int Genet. 2013;7:159-166.

72. Nussbaumer C, Gharehbaghi-Schnell E, Korschineck I. Messenger RNA profiling: a novel method for body fluid identification by real time PCR. Forensic Sci Int. 2006;157:181-186.

73. Hanson EK, Ballantyne J. Multiplex high resolution melt (HRM) messenger RNA profiling analyses for body fluid identification. Forensic Sci Int Genet. Suppl Ser. 2013;4:e125-e126.

74. Harteveld J, Lindenbergh A, Sijen T. RNA cell typing and DNA profiling of mixed samples: can cell types and donors be associated? Sci Justice. 2013;53:261-269.

75. Su CW, Li CY, Lee JCI, et al. A novel application of real-time RTLAMP for body fluid identification: using HBB detection as the model. Forensic Sci Med Pathol. 2015;11(2):208-215.

76. Moreno LI, Tate CM, Knott EL, et al. Determination of an effective housekeeping gene for the quantification of mRNA for forensic applications. J Forensic Sci. 2012;57:1051-1058.

77. Jakubowska J, Maciejewska A, Pawlowski R, Bielawski KP. mRNA profiling for vaginal fluid and menstrual blood identification. Forensic Sci Int Genet. 2013;7:272-278.

78. Donfack J, Wiley A. Mass spectrometry based cDNA profiling as a potential tool for body fluid identification. Forensic Sci Int Genet. 2015;16:112-120.

79. Bustin SA, Benes V, Nolan T, Pfaffl MW. Quantitative real time RT PCR - a perspective. J Mol Endocrinol. 2005;34:597-601.

80. Park NJ, Zhou X, Yu T, et al. Characterization of salivary RNA by cDNA library analysis. Arch Oral Biol. 2007;52:30-35.

81. Park SM, Park SY, Kim JH, et al. Genome-wide mRNA profiling and multiplex quantitative RT-PCR for forensic body fluid identification. Forensic Sci Int Genet. 2013;7:143-150.

82. Hanson EK, Ballantyne J. Highly specific mRNA biomarkers for the identification of vaginal secretions in sexual assault investigations. Sci Justice. 2013;53:14-22.

83. Sakurada K, Akutsu T, Watanabe K, Fujinami Y, Yoshino M. Expression of statherin mRNA and proteins in nasal and vaginal secretions. Leg Med. 2011;13:309-313.

84. Cossu C, Germann U, Kratzer A, Baer W, Haas C. How specific are the vaginal secretion mRNA markers HBD1 and MUC4. Forensic Sci Int Genet Suppl Ser. 2009;2:536-537.

85. Fleming RI, Harbison SA. The use of bacteria for the identification of vaginal secretions. Forensic Sci Int Genet. 2010;4:311-315.

86. Akutsu T, Motani H, Watanabe K, Iwase H, Sakurada K. Detection of bacterial 16S ribosomal RNA genes for forensic identification of vaginal fluid. Leg Med. 2012;14:160-162. 
87. Giampaoli S, Berti A, Valeriani F, et al. Molecular identification of vaginal fluid by microbial signature. Forensic Sci Int Genet. 2012;6: 559-564.

88. Doi M, Gamo S, Okiura T, Nishimukai H, Asano M. A simple identification method for vaginal secretions using relative quantification of Lactobacillus DNA. Forensic Sci Int Genet. 2014;12:93-99.

89. Giampaoli S, Alessandrini F, Berti A, et al. Forensic interlaboratory exercise of the ForFLUID kit for vaginal fluids identification. J Forensic Leg Med. 2014;21:60-63.

90. Schulz MM, Buschner MGD, Leidig R, et al. A new approach to the investigation of sexual offenses-cytoskeleton analysis reveals the origin of cells found on forensic swabs. J Forensic Sci. 2010;55: 492-498.

91. Simons JL, Vintiner SK. Efficacy of several candidate protein biomarkers in the differentiation of vaginal from buccal epithelial cells. J Forensic Sci. 2012;57:1585-1590.

92. Fleming RI, Harbison SA. The development of an mRNA amplification positive control for the identification of body fluids. Can J For Sci J. 2014;47:37-45.

93. Lin MH, Jones DF, Fleming R. Transcriptomic analysis of degraded forensic body fluids. Forensic Sci Int Genet. 2015;17:35-42.

94. Zubakov D, Kokmeijer I, Ralf A, et al. Towards simultaneous individual and tissue identification: a proof-of-principle study on parallel sequencing of STRs, amelogenin, and mRNAs with the Ion Torrent PGM. Forensic Sci Int Genet. 2015;17:122-128.

95. Malkov VA, Serikawa KA, Balantac N, et al. Multiplexed measurements of gene signatures in different analytes using the NanostringnCounter $^{\mathrm{TM}}$ assay system. BMC Res Notes. 2009;2:80.

96. Brumbaugh CD, Kim HJ, Giovacchini M, Pourmand N. NanoStriDE: normalization and differential expression analysis of NanoString nCounter data. BMC Bioinformatics. 2011;12:479.

97. Park JL, Park SM, Kim JH, et al. Forensic body fluid identification by analysis of multiple RNA markers using NanoString technology. Genomics Inform. 2013;11:277-281.

98. Danaher P, White RL, Hanson EK, Ballantyne J. Facile semi-automated forensic body fluid identification by multiplex solution hybridization of NanoString ${ }^{\circledR}$ barcode probes to specific mRNA targets. Forensic Sci Int Genet. 2015;14:18-30.

99. Lagos-Quintana M, Rauhut R, Lendeckel W, Tuschl T. Identification of novel genes coding for small expressed RNAs. Science 2001;294: $853-858$.

100. miRBase. Available from: http://www.mirbase.org/. Accessed June 3, 2015.

101. Omelia EJ, Uchimoto ML, Williams G. Quantitative PCR analysis of blood and saliva specific microRNA markers following solid-phase DNA extraction. Anal Biochem. 2013;435:120-122.

102. Hanson EK, Lubenow H, Ballantyne J. Identification of forensically relevant body fluids using a panel of differentially expressed microRNAs. Anal Biochem. 2009;387:303-314.

103. Zubakov D, Boersma AW, Choi Y, van Kuijk PF, Wiemer EA, Kayser M. MicroRNA markers for forensic body fluid identification obtained from microarray screening and quantitative RT-PCR confirmation. Int J Leg Med. 2010;124:217-226.

104. Park JL, Park SM, Kwon OH, et al. Microarray screening and qRT-PCR evaluation of microRNA markers for forensic body fluid identification. Electrophoresis. 2014;35:3062-3068.

105. Courts C, Madea B. Specific micro-RNA signatures for the detection of saliva and blood in forensic body-fluid identification. J Forensic Sci. 2011;56:1464-1470.

106. Wang Z, Luo H, Pan X, Liao M, Hou Y. A model for data analysis of microRNA expression in forensic body fluid identification Forensic Sci Int Genet. 2012;6:419-423.

107. Uchimoto ML, Beasley E, Coult N, Omelia EJ, World D, Williams G. Considering the effect of stem-loop reverse transcription and real-time PCR analysis of blood and saliva specific microRNA markers upon mixed body fluid stains. Forensic Sci Int Genet. 2013;7:418-421.
108. Meer D, Uchimoto ML, Williams G. Simultaneous analysis of micro RNA and DNA for determining the body fluid origin of DNA profiles. J Forensic Sci. 2013;58:967-971.

109. Sauer E, Madea B, Courts C. An evidence based strategy for normalization of quantitative PCR data from miRNA expression analysis in forensically relevant body fluids. Forensic Sci Int Genet. 2014;11: 174-181.

110. Sauer E, Babion I, Madea B, Courts C. An evidence based strategy for normalization of quantitative PCR data from miRNA expression analysis in forensic organ tissue identification. Forensic Sci Int Genet. 2014;13:217-223.

111. Paterson SK, Jenson CG, Vintiner SK, McGlashan SR. Immunohistochemical staining as a potential method for the identification of vaginal epithelial cells in forensic casework. J Forensic Sci. 2006;51:1138-1143.

112. Thorogate R, Moreira JCS, Jickells S, Miele MMP, Daniel B. A novel fluorescence-based method in forensic science for the detection of blood in situ. Forensic Sci Int Genet. 2008;2:363-371.

113. Lynch L, Gamblin A, Vintiner S, Simons J. STR profiling of epithelial cells identified by X/Y FISH labelling and laser microdissection using standard and elevated PCR conditions. Forensic Sci Int Genet. 2015;16:1-7.

114. Fleming RI, Harbison SA, Lin MH. New RNA methods for the identification of body fluids and cell types. Forensic Sci Int Genet Suppl Ser. 2013;4:e87-e88.

115. Williams E, Lin MH, Harbison SA, Fleming RI. The development of a method of suspension RNA-FISH for forensically relevant epithelial cells using LNA probes. Forensic Sci Int Genet. 2014;9:85-92.

116. Frumkin D, Wasserstrom A, Budowle B, Davidson A. DNA methylation based forensic tissue identification. Forensic Sci Int Genet. 2011;5:517-524.

117. Madi T, Balamurugan K, Bombardi R, Duncan G, McCord B. The determination of tissue-specific DNA methylation patterns in forensic biofluids using bisulfite modification and pyrosequencing. Electrophoresis. 2012;33:1736-1745.

118. An JH, Choi A, Shin KJ, Yang WI, Lee HY. DNA methylationspecific multiplex assays for body fluid identification. Int J Leg Med. 2013;127:35-43

119. Park JL, Kwon OH, Kim JH, et al. Identification of body fluid-specific DNA methylation markers for use in forensic science. Forensic Sci Int Genet. 2014;13:147-153.

120. Lee HY, Park MJ, Choi A, An JH, Yang WI, Shin KJ. Potential forensic applications of DNA methylation profiling to body fluid identification. Int J Leg Med. 2012;126:55-62.

121. Balamurugan K, Bombardi R, Duncan G, McCord B. Identification of spermatozoa by tissue-specific differential DNA methylation using bisulfite modification and pyrosequencing. Electrophoresis. 2014;35:3079-3086.

122. Lee HY, An JH, Yung SE, et al. Genome wide methylation profiling and a multiplex construction for the identification of body fluids using epigenetic markers. Forensic Sci Int Genet. 2015;17:17-24.

123. Kader F, Ghai M. DNA methylation and application in forensic sciences. Forensic Sci Int. 2015;249:255-265.

124. LaRue BL, King JL, Budowle B. A validation study of the Nucleix DSI-Semen kit-a methylation-based assay for semen identification. Int J Leg Med. 2013;127:299-308.

125. Florath I, Butterbach K, Muller H, Bewerunge-Hudler M, Brenner H. Cross-sectional and longitudinal changes in DNA methylation state with age: an epigenome-wide analysis revealing over 60 novel ageassociated CpG sites. Hum Mol Genet. 2014;23:1186-1201.

126. Bartling CM, Hester ME, Bartz J, Heizer E Jr, Faith SA. Nextgeneration sequencing approach to epigenetic-based tissue source attribution. Electrophoresis. 2014;35:3096-3101.

127. Human Microbiome Project Consortium. Structure, function and diversity of the healthy human microbiome. Nature. 2012;486: 207-214. 
128. Kuczynski J, Costello EK, Nemergut DR, et al. Direct sequencing of the human microbiome readily reveals community differences. Genome Biol. 2010;11:210.

129. Jorth P, Turner KH, Gumus P, et al. Meta-transcriptomics of the human oral microbiome during health and disease. MBio. 2014;5: e01012-e01014.

130. White BA, Creedon DJ, Nelson KE, Wilson BA. The vaginal microbiome in health and disease. Trends Endocrinol Metab. 2011;22: 389-393.

131. Huse SM, YeY, Zhou Y, Fodor AA. A core human microbiome as viewed through 16S rRNA sequence clusters. PLoS One. 2012;7:e34242.

132. Antonio MAD, Hawes SE, Hillier SL. The identification of vaginal Lactobacillus species and the demographic and microbiologic characteristics of women colonized by these species. $J$ Infect Dis. 1999; 180:1950-1956.

133. Hammerschlag MR, Alpert S, Rosner I, et al. Microbiology of the vaginal in children: normal and potentially pathogenic organisms. Paediatrics. 1978;62:57-62.

134. Power DA, Cordiner SJ, Kieser JA, Tompkins GR, Horswell J. PCR based detection of salivary bacteria as a marker of expirated blood. Sci Justice. 2010;50:59-63.

135. Nakanishi H, Kido A, Ohmoris T, et al. A novel method for the identification of saliva by detecting oral streptococci using PCR. Forensic Sci Int. 2009;183:20-23.

136. Donaldson AE, Taylor MC, Cordiner SJ, Lamont IL. Using oral microbial DNA analysis to identify expirated blood spatter. Int $J$ Leg Med. 2010;124:569-576.

137. Nakanishi H, Shojo H, Ohmori T, et al. Identification of feces by detection of Bacteroides genes. Forensic Sci Int Genet. 2013;7:176-179.

138. Choi A, Shin KJ, Yang WI, Lee HY. Body fluid identification by integrated analysis of DNA methylation and body fluid-specific microbial DNA. Int J Leg Med. 2014;128:33-41.

139. Fierer N, Hamady M, Lauber CL, Knight R. The influence of sex, handedness and washing on the diversity of hand surface bacteria Proc Natl Acad Sci U S A. 2008;105:17994-17999.

140. Fierer N, Lauber CL, Zhou N, McDonald D, Costello EK, Knight R. Forensic identification using skin bacterial communities. Proc Natl Acad Sci U S A. 2010;107:6477-6481.

141. Benschop CC, Quaak FC, Boon ME, Sijen T, Kuiper I. Vaginal microbial flora analysis by next generation sequencing and microarrays: can microbes indicate vaginal origin in a forensic context? Int J Leg Med. 2012;126:303-310

142. Peticolas WL. Application of Raman spectroscopy to biological macromolecules. Biochimie. 1975;57:417-428.

143. Boyd S, Bertino MF, Ye D, White LS, Seashols SJ. Highly sensitive detection of blood by surface enhanced Raman scattering. J Forensic Sci. 2013;58:753-756.

144. Sikirzhytskaya A, Sikirzhytski V, Lednev IK. Raman spectroscopic signature of vaginal fluid and its potential application in forensic body fluid identification. Forensic Sci Int. 2012;216:44-48.

145. Virkler K, Lednev IK. Forensic body fluid identification: the Raman spectroscopic signature of saliva. Analyst. 2010;135:512-517.
146. Sikirzhytski V, Sikirzhytskaya A, Lednev IK. Multidimensional Raman spectroscopic signature of sweat and its potential application to forensic body fluid identification. Anal Chim Acta. 2012;718:78-83.

147. McLaughlin G, Doty KC, Lednev IK. Raman spectroscopy of blood for species identification. Anal Chem. 2014;86:11628-11633.

148. Sikirzhytskaya A, Sikirzhytski V, McLaughlin G, Lednev IK. Forensic identification of blood in the presence of contaminations using Raman microspectroscopy coupled with advanced statistics: effect of sand, dust, and soil. J Forensic Sci. 2013;58:1141-1148.

149. De Wael K, Lepot L, Gason F, Gilbert B. In search of blood-detection of minute particles using spectroscopic methods. Forensic Sci Int. 2008; 180:37-42.

150. Sikirzhytskaya A, Sikirzhytski V, Lednev, IK. Raman spectroscopy coupled with advanced chemometrics for forensic analysis of semen and blood mixtures. Spectroscopy. 2013;28:25-29.

151. Orphanou CM. The detection and discrimination of human body fluids using AFT-FT-IR spectroscopy. Forensic Sci Int. 2015;252:e10-e16.

152. Pusch W, Wurmbach JH, Thiele H, Kostrzewa M. MALDI TOF mass spectrometry based SNP genotyping. Pharmacogenomics. 2002;3: 537-548.

153. Krebs S, Seichter D, Forster M. Genotyping of dinucleotide tandem repeats by MALDI mass spectrometry of ribozyme cleaved RNA transcripts. Nat Biotechnol. 2001;19:877-880.

154. Edwards JR, Ruparel H, Ju J. Mass spectrometry DNA sequencing. Mutat Res. 2005;573:3-12.

155. Yang H, Zhou B, Prinz M, Siegel D. Proteomic analysis of menstrual blood. Mol Cell Proteomics. 2012;11:1024-1035.

156. Yang H, Zhou B, Deng H, Prinz M, Siegel D. Body fluid identification by mass spectrometry. Int J Leg Med. 2013;127:1065-1077.

157. Scano P, Loci E, Noto A, et al. ${ }^{1} \mathrm{H}$ NMR metabolite fingerprinting as a new tool for body fluid identification in forensic science. Magn Reson Chem. 2013;51:454-462.

158. Kotowski TM, Grieve MC. The use of micro-spectrophotometry to characterise microscopic amounts of blood. J Forensic Sci. 1986;31: 1079-1085.

159. Soukos NS, Crowley K, Bamberg MP, et al. A rapid method to detect dried saliva stains swabbed from human skin using fluorescence spectroscopy. Forensic Sci Int. 2000;114:133-138.

160. Frascione N, Gooch J, Daniel B. Enabling fluorescent biosensors for the forensic identification of body fluids. Analyst. 2013;138 7279-7288.

161. Goldman ER, Mattoussi H, Anderson GP, Medintz IL, Mauro JM. Fluoro-immunoassays using antibody-conjugated quantum dots Methods Mol Bio. 2005;303:19-34.

162. Frascione N, Pinto V, Daniel B. Development of a biosensor for human blood: new routes to body fluid identification. Anal Bioanal Chem. 2012;404:23-28.

163. LaRue BL, Moore A, King JL, Marshall PL, Budowle B. An evaluation of the RapidHIT ${ }^{\circledR}$ system for reliably genotyping reference samples. Forensic Sci Int Genet. 2014;13:104-111.
Research and Reports in Forensic Medical Science

\section{Publish your work in this journal}

Research and Reports in Forensic Medical Science is an international, peer-reviewed, open access journal publishing original research, reports, reviews and commentaries on all areas of forensic medical science. The manuscript management system is completely online and includes a

\section{Dovepress}

very quick and fair peer-review system. Visit http://www.dovepress.com/ testimonials.php to read real quotes from published authors. 